\title{
Construal Of Voluntary Environmental Program Participation In The Canadian Residential Construction Industry
}

\author{
Dustin Quirk D.B.A., Red Deer College, Canada \\ Devi Jankowicz, Ph.D., Heriot-Watt University, Edinburgh, UK
}

\begin{abstract}
This is a study of sensemaking of how Canadian new home builders construe their decision to participate in a voluntary environmental program (Built Green Canada). The Repertory Grid Technique was the data collection method. Findings from 32 interviews revealed a number of themes that decision makers used to make sense of their decision to participate in the program. The most prevalent views related to seeing the decision as a function of being a leader or innovator in the industry and using the program as a marketing and sales tool. Furthermore, themes that were seen as important related to legitimacy/authenticity/integrity and environmental impact. An assessment of which drivers/pressures were important to decision makers in making the decision to join the program was also undertaken. Important drivers/pressures included handling competition, appealing to customers, acquiring technical knowledge, obtaining publicity, building corporate culture/identity, and obtaining third party certifications. The findings are significant as it assists in refining the emergent field of environmental decision making and planning. The results are also useful for industry, voluntary environmental program organizations, and government policy makers to provide them with a better understanding of participant motivations leading to program improvements and better marketing of these programs.
\end{abstract}

Keywords: Voluntary Environmental Programs; Repertory Grid Technique; Building Industry; Canada

\section{INTRODUCTION}

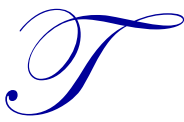

his is a study of sensemaking (Weick, 1995) in the home building industry using Personal Construct Theory (Kelly, 1955 and 1963) to examine the ways in which home builders construe their decision to participate in a voluntary environmental program (see Appendix 1 for a glossary of key terms). This research offers new insights on management thinking about voluntary environmental programs in the field of residential construction (new home building). 2004):

A voluntary environmental program is defined as a voluntary code with the following characteristics (Webb,

i. $\quad$ commitments are not required by legislation or regulations;

ii. $\quad$ they are agreed to by one or more individuals or organizations;

iii. they are intended to influence or control behaviour; and

iv. they are to be applied in a consistent manner or to reach a consistent outcome.

As its name would suggest, voluntary environmental programs are not mandated and thus require a purposeful decision to join (Webb, 2004). The research takes place within the context of the Canadian home building industry (residential construction) examining the Built Green Canada program. Built Green Canada is a voluntary environmental program that provides third party certification for homes that are built environmentally 
friendly in terms of construction practices and ongoing operations (e.g. energy efficient and indoor air quality) (Built Green Canada, 2011a).

Housing is a basic need. It is also a significant source of economic activity and employment. Economic activity related to the Canadian residential housing industry, including the construction, renovation and the sale of homes, represents over 20 per cent of the nation's gross domestic product (Canada Mortgage and Housing Corporation, 2010). The competitive landscape of the Canadian residential housing industry meets Porter's (1980) definition of a fragmented industry as it is comprised of a large number of small and medium sized firms that are privately owned where no single firm has a significant market share. Although they are mostly small and medium sized firms, Canadian home builders are big employers. Estimates based on Canada's 2006 Census data, place about 300,000 people working directly in the industry (Canada Mortgage and Housing Corporation, 2010). This study takes place within the context of this economically important industry.

Resource consumption for new home construction and the ongoing energy use for the operation of people's homes (i.e. heating, cooling, hot water, appliances and lighting) represent a significant impact on the environment. Global building construction is estimated to consume 40 per cent of the material and energy produced each year (Kansal and Kadambri, 2010). In a time of dwindling resources and higher energy prices, sustainability and energy conservation are growing issues.

The aim is to understand how home builders make sense of the decision to take part in the Built Green Canada voluntary environmental program. The literature suggests a variety of influences on the decision to join, which can be regarded as a set of pressures, influences, and drivers towards that decision. It also suggests that sensemaking theory, and particularly, the approach taken from Kelly's personal construct psychology, provide a good way of examining how these pressures are handled, and that there is a great value in understanding the decision from the perspective of the participants themselves. Following the personal construct psychology approach, this is not so much a study of motivation, but rather a focus on cognition or the reasons the home builders give themselves for participating in the program, based on what they know, what they think they know, and about their day-to-day experience with the program.

\section{Background}

\section{Going Green}

A definition of what it means for business to 'go green' or adopt a proactive environmental response is a useful starting point in understanding this topic. Henriques and Sadorsky (1996: 382) define an environmentally responsive firm as, "... a firm that has formulated an official plan for dealing with environmental issues". Hart (1997) identified three stages of environmental strategy. These include pollution prevention, product stewardship, and the development of clean technology. Bansal and Roth (2000: 717) define it as "...a set of corporate initiatives aimed at mitigating a firm's impact on the natural environment." These initiatives were described to comprise changes to the firm's products, processes, and policies. The authors listed examples that included reducing energy use and waste generation, using ecologically sustainable resources, and implementing an environmental management system/plan. Tran (2009) identified that there are both mandated (meeting environmental legislative requirements) and voluntary aspects to going green. Tran (2009: 24) also defined green management as, “...simply the rethinking, or more accurately, being more mindful of how organizations are operating (or a lack thereof) with respect to the environment." Based on this, the terms 'going green', 'environmental management' and 'proactive environmental response' can be used interchangeably to describe initiatives that a firm is taking to reduce its environmental footprint whether it is by product and/or process improvements or modifications. This wide ranging definition includes such operational activities as emissions reductions, reduced energy and resource consumption, and reduced waste generation to developing longer lasting, more efficient, and/or more environmentally responsible products (Henriques and Sadorsky, 1996; Bansal and Roth, 2000; Tran, 2009).

\section{Built Green Canada}

While governments in Canada impose minimum building code requirements on new homes, these are largely focused on safety, accessibility and structural issues (Alberta Ministry of Municipal Affairs, 2011). 
Mandated energy efficiency requirements are minimal (e.g. minimum requirements for thermal insulation) and energy efficient building codes are still in development (Alberta Ministry of Municipal Affairs, 2012). In addition, building codes provide no guidance on the conservation of resources used during the actual construction process.

In response, some individual builders on their own recognisance have adopted "green" building practices and enhanced energy efficient features in their products. Other builders have opted to join industry sponsored voluntary environmental programs (the focus of this study). The goal of either of these environmental strategies is to meet the environmentally friendly desires of new home purchasers as well as assist in marketing their products and to achieve premium pricing through environmental differentiation (Siegel, 2009).

Built Green Canada, the focus of this research, is an example of a voluntary environmental program that provides third party certification of environmental performance. The program is marketed to new home builders as adding value to new home construction through the promotion and recognition that a Built Green Canada certified home is resource/energy efficient and constructed in an environmentally friendly manner. The program's stated purpose is to promote, encourage, enable and recognize environmentally responsible residential home construction practices through five key areas: environmental concern, increased energy efficiency and reduced pollution, healthier indoor air, reduction in water usage, and preservation of natural resources (Built Green Canada, 2011b).

\section{Environmental Competitiveness and Drivers}

For many businesses the idea of adopting more environmentally friendly practices is seen as an additional cost that will impact the bottom line (Palmer et al, 1995). In other words, some firms view the costs associated with pollution abatement, environmental regulatory compliance, and waste reduction as additional expenses that erode profitability. There is a growing field of research; however, that provides the argument that proactive environmental strategies lead to innovation and competitive advantage (Hart, 1995; Porter and van der Linde, 1995; Sharma and Vredenburg, 1998; Branco and Rodrigues, 2006; Chen, 2008) improving firm performance (Stanwick and Stanwick, 2001; Menguc and Ozanne, 2005; Molina-Azorín et al, 2009; Clarkson et al, 2011).

Previous research exploring firms and the drivers/pressures leading to environmental friendly strategies has revealed a number of internal and external pressures including regulatory/legislative pressure, stakeholder pressure (including customer pressure), competitive pressure, and ethical motivations of the organization (Arora and Cason, 1996; Henriques and Sadorsky, 1996; Bansal and Roth, 2000; Videras and Alberini, 2000; Annandale et al, 2004; González-Benito and González-Benito, 2004; Lynes and Dredge, 2006; Mikler, 2007; Paulraj, 2009; Wu, 2009; Blackman et al, 2010; Sharma and Sharma, 2011). These drivers of environmental response were first clearly highlighted in Bansal and Roth's (2000) Model of Corporate Ecological Responsiveness. Bansal and Roth (2000) identified the drivers of ecological response as legislation, stakeholder pressures, economic opportunities and ethical motives.

With respect to prior studies on voluntary environmental programs Annandale et al (2004) found many of the previously mentioned drivers like pressure from customers, management, the public and regulators; corporate culture; and cost savings to be influential. In addition, Darnall et al (2000: 2) in their study of ISO 14001 (a voluntary environmental management system) reported reasons for joining the program included, “...evidence suggesting that international trade influences, supplier references, public relations pressures, customer preferences, shareholder interests, environmental performance factors, compliance pressure, and other motives may play a part." Henriques and Sadorsky (2008) identified the main motivators to participate in a unilateral voluntary environmental program are to pre-empt or influence government regulation, cost efficiency, to improve stakeholder relations, and the possibility of receiving technical assistance or an incentive mechanism. These motivations are designed to build competitive advantage (Hart, 1995) via increasing a firm's internal efficiency and external legitimacy (Henriques and Sadorsky, 2008).

By linking this assessment of environmental drivers/pressures acting on firms with the notion of joining a voluntary environmental program, this study's focus is on voluntary participation in light of such drivers/pressures. This research is also designed to address the concerns raised in prior studies calling for a more in-depth understanding of the issue such as Bansal and Roth (2000), Prakash (2001), Khana et al (2007) and HowardGrenville et al (2008). 


\section{RESEARCH METHODOLOGY}

\section{Research Questions}

The aim is to understand a home builder's decision to take part in a voluntary environmental program (Built Green Canada).

The objective is therefore to identify the ways in which participants construe and make sense of the drivers and pressures to join. This leads to two research questions in particular.

1. How do participating home builders construe and make sense of the drivers/pressures to which they are exposed in making the decision to participate in a voluntary environmental program (Built Green Canada)?

Taking a constructivist approach will provide insights on how decision makers 'see' or make sense of these drivers/pressures (Georg and Füssel, 2000).

Moreover, as it is intended to pay particular attention to the relative level of importance that home builders attribute to the drivers/pressures to participate which the literature suggests in general are important in voluntary environmental program participation, the first research question was elaborated into a second further research question:

2. To assess the relative level of importance of the drivers/pressures identified in the literature that decision makers in the home building industry attribute to their decision to participate in a voluntary environmental program (Built Green Canada).

This research question is drawn from the existing literature on the motivators driving participation in voluntary programs.

In summary, the first research question is designed to gain an understanding of how home builders think and attribute meaning to their decision to participate in a voluntary environmental program. In other words, how they cognitively categorize the various drivers/pressures to participate. The second research question is designed to assess the relative level of importance that home builders attribute to the drivers/pressures to participate.

\section{Methods - Repertory Grid Technique}

The epistemological stance of this research is interpretive in the phenomenological and constructivist research tradition. As the aim of this research is to identify the construal of drivers/pressures impacting decision making, a phenomenological and constructivist approach is appropriate.

According to Patton (2002: 482), "Phenomenological analysis seeks to grasp and elucidate the meaning, structure, and essence of the lived phenomenon for a person or group of people." Furthermore, Snape and Spencer (2003: 12) define the aim of phenomenological research to "Understand the 'constructs' people use in everyday life to make sense of their world." It is this very nature of personal constructs and sensemaking by decision makers in the home building industry that is the focus of this research. Developing an understanding of how individuals make meaning leads to the topic of constructivism. Constructivism involves the making of meaning. According to Crotty (1998: 9), "Meaning is not discovered but constructed." Snape and Spencer (2003: 12) define constructivism as, "Displaying 'multiple constructed realities' through the shared investigation (by researchers and participants) of meanings and explanations." Kelly's PCP embodies constructivist elements by providing an enunciation of an individually-based constructivist epistemology in the form of a theoretical statement (the Fundamental Postulate and 11 corollaries) (Kelly, 1955; Raskin, 2011). The construction corollary is one of the basic tenets of PCP and PCT (Butt and Burr, 2004). Kelly (1955) defined the construction corollary as, "A person anticipates events by construing their replications." Basically, the construing process involves placing meaning or interpretation on events through internal representations which recognize recurrent patterns in experience (Kelly, 1955; Jankowicz, 2004). Kelly's PCP and PCT involves sensemaking as it is concerned with how people construct meaning out of events in a continuous and ongoing manner. The research methodology, detailed below, incorporates a constructivist technique based on PCT using the Repertory Grid Technique. Since this study endeavours to 
understand both constructs and the making of sense, it aligns with the phenomenological/constructivist epistemologies.

Repertory Grid Technique (RGT) was used to collect data in this constructivist approach. The repertory grid is a technique that was developed by psychologist George Kelly as an instrument for eliciting personal constructs (Kelly, 1955 and 1963). The repertory grid also serves as a cognitive mapping tool (Tan and Hunter, 2002; Fassin and Van Rossem, 2009) that provides for a precise and explicit articulation of an individual's personal constructs (Jankowicz, 1987). This mapping and expression of how decision makers construe drivers/pressures to participate is essential to answering the research questions. The RGT is also in alignment with the research questions as it is consistent with an interpretive perspective with the aim of understanding how decision makers make sense of the influences on their decision to participate in the program (Fransella et al, 2004; Fassin et al, 2011).

RGT provides for both qualitative and quantitative data collection in the interviews providing for concurrent triangulation (Creswell, 2003). Another advantage of the RGT is that it helps remove the influence of the researcher's frame of reference on the observations (Diaz de Leon and Guild, 2003). The RGT is also a method proven to minimize researcher bias compared to other mapping methods (Fassin et al, 2011). In addition, the RGT is useful for addressing the research questions as RGT has a way of uncovering the insights of individuals that inform their decision making while an in-depth interview may not access the underlying reality of the situation (Rogers and Ryals, 2007). Also making the RGT appropriate is that it is a tool that can bring forth the thinking that participants possess but are unable to articulate (Diaz de Leon and Guild, 2003). Furthermore, Rogers and Ryals (2007) mentioned that the technique allows the researcher to get beneath what an interviewee might view as the right answer. In this sense, RGT is useful to address social desirability bias with interviewees (Jankowicz, 2004). Finally, the RGT is also appropriate as it has proven successful in business research related to market research, business ethics, and organizational and business applications (Fransella et al, 2004; Jankowicz, 2004; Fassin et al, 2011).

\section{Data Collection}

In alignment with the phenomenological and constructivist research paradigms, data was collected through face-to-face interviews with 32 builder members of the Built Green Canada program in the Alberta residential home construction industry. Limiting participation to Built Green Canada members is required for reasons of accessibility (outlined below) and since participating members are the focus of this research. Patton (2002) would describe this technique as a purposeful sample. A prescribed convenience selection criterion was used to request interviews from all firms from the Built Green Canada membership directory of builder members located within the CalgaryEdmonton corridor in Alberta (within a 160 kilometre radius of Red Deer, Alberta). The 32 participants who agreed to be interviewed represented a 25 per cent response rate.

A comparative case study approach was considered that would compare construing in firms participating in the Built Green Canada program with non-participants, but the previously mentioned technique was chosen instead due to accessibility issues and the nature of the research questions. In terms of accessibility, securing interviews from firms not participating in the voluntary environmental program was problematic. This relates to the issue of relevance which is positively correlated with response rates (Anseel et al, 2010). As Anseel et al (2010: 337) state, "Topic salience is a type of interaction between target population and researcher interest, and is assumed to result in high motivation and involvement of the participants." In other words, home builders who are not members of the Built Green Canada program have less interest in the program and as a result are less motivated to be involved in the research.

An initial attempt was made to contact 49 non-participating firms. From that group not a single firm was willing to conduct an interview (a zero percent response rate by non-participants). Lindebaum's and Cassell's (2012) study on emotional intelligence in the male-dominated construction industry highlights another contributing factor in that construction managers are less expressive; and this is no less so for the Canadian construction industry in particular. This could contribute to their reluctance to participate in research about perceptions and reflecting on one's sense making. 
This approach is not without risk. Limitations of using multiple case studies in building theory include the development of overly complex theory and theories that are narrow in focus, in other words, modest theories about specific phenomena (Eisenhardt, 1989). This limitation poses a risk in this study as this research is focused on a specific voluntary environmental program (Built Green Canada) within the context of a specific industry and geography (new home building in Alberta). However, the use of multiple case studies is appropriate, due to the specific applied nature of this research. In addition, multiple case studies are warranted as there is an opportunity to provide further empirical substantiation, to provide freshness in perspective, and to offer new insights (Eisenhardt, 1989).

The typical multistep process for completing the repertory grids was utilized to collect the data (Fransella et al, 2004; Jankowicz, 2004; Rogers and Ryals, 2007). In the interviews, the elements or drivers/pressures identified in the literature (see Table 1) were provided and explained and the constructs were elicited from triading elements (Jankowicz, 2004). In total, the interviews generated a total of 265 elicited constructs.

Table 1. Elements

\begin{tabular}{cl}
\hline Code & \multicolumn{1}{c}{ Element } \\
\hline E1 & Pre-empting/influencing government legislation (e.g. building code changes) \\
E2 & Creating cost efficiencies for your organization \\
E3 & Handling competition \\
E4 & Appealing to customers \\
E5 & Responding to suppliers/trades \\
E6 & Acquiring technical knowledge \\
E7 & Accessing Government/CMHC Incentives \\
E8 & Obtaining publicity \\
E9 & Building corporate culture/identity \\
E10 & Obtaining third party certification \\
\hline
\end{tabular}

One construct was provided at the end of each interview as an 'overall summary construct'. This was worded 'Overall, important to my decision to participate - Overall, less important to my decision to participate'. Its purpose was twofold. First, to indicate the relative importance of constructs to the individuals who provided them, in the content analysis used to aggregate them across the sample as a whole- following a technique developed by Honey (1979). This addresses the first research question. Second, to allow for an assessment of the relative importance of each of the elements - in other words, to provide a way to determine which drivers/pressures are important to the home builders- which answers the second research question.

\section{Data Analysis}

Once the data was collect through the RGT interviews, the main focus was on aggregate grid (cross-case) data analysis utilizing prescribed RGT analysis methodologies (Jankowicz, 2004). By conducting cross-case analysis, not only did the examination provide an understanding of the construal of drivers/pressures within individual decision makers, but it provided for deeper understanding and to some extent generalizeability (Miles and Huberman, 1994). It should be noted that the unit of analysis in RGT is the construct (Jankowicz, 2004), not the decision maker nor the company, and thus the main content analysis focuses on the constructs.

The data was analyzed through a content analysis utilizing the Core-Categorization Procedure (Jankowicz, 2004: 149). Content analysis is a sensemaking effort that attempts to identify core consistencies and meaning (Patton, 2002). According to Patton (2002: 453), "The core meanings found through content analysis are often called patterns or themes." Content analysis can be used to analyze aggregate RGT interview data. According to Jankowicz (2004: 148), "Content analysis is a technique in which the constructs of all interviewees are pooled, and categorized according to the meanings they express." In this sense, the aggregate RGT interviews are analysed to look for patterns in how decision makers construe the drivers/pressures to participate in a voluntary environmental program and how they make sense of that decision. The content analysis techniques used to analyze the RGT interview grids comprises both Honey's (1979) Content Analysis procedures and Bootstrapping Techniques as detailed by Jankowicz (2004). 
In addition, the content analysis provided for "measures of prevalence" (i.e. how frequent a construct occurred in the RGT interviews) and "measures of importance" (i.e. how important the construct was to the interviewee). Honey's (1979) technique provided two methods to assess the "measure of importance" of the constructs through the calculation of average percent similarity scores and the assignment of H-I-L values (high, intermediate and low values). The average percent similarity scores calculated in a content analysis of multiple grids are based on the relative importance of constructs by utilizing a supplied construct that was common to all of the grid interviews. In this study the supplied construct was 'Important to my decision to participate - Less important to my decision to participate'. Not only does this supplied construct provide an overall summary of the interviewee's views of each element, it also provides the ability to assess the level that ratings on the elicited constructs match the ratings on the overall supplied construct. This involves calculating percent similarity scores for each elicited construct with respect to the overall supplied construct (Jankowicz, 2004).

H-I-L value assignment for "measures of importance" in Honey's (1979) technique are designed to take the interviewee's personal metric into account by dividing up their constructs into thirds. These groupings account for the constructs with the highest percent similarity scores, intermediate percent similarity scores, and lowest percent similarity scores. The assignment of H-I-L values allows for the aggregation of the grid data representing the categorised views of all the interviewees while preserving each individual's view of the topic (Jankowicz, 2004). In this sense, a percent similarity score of, e.g., $80 \%$ may be high for one person but low for another, and the H-I-L value coding will preserve this information to aid in the drawing of conclusions from the content analysis (Jankowicz, 2004).

A content-analysis reliability check was also utilized (Jankowicz 2004: 155-163) to ensure reliability of the data. A final percent agreement score of 96.2 percent with inter-rater reliability scores of 0.96 for Cohen's Kappa and 0.94 for the Perreault-Leigh Index (Perreault-Leigh Index 95\% Confidence Interval of 0.92 to 0.97). These results exceeded the benchmarks for both percent agreement and inter-rater reliability scores (Jankowicz, 2004: 161163; Perreault and Leigh, 1989: 147). In other words, the final results of the categorization were reliable.

\section{FINDINGS AND DISCUSSION}

\section{Constructs}

The RGT interviews generated 265 elicited constructs which were categorized into 14 themes. The prevalence/frequency and importance of these are summarized below in Table 2.

Table 2. Content Analysis Summary

\begin{tabular}{lcccc}
\hline \multirow{2}{*}{ Category } & \multicolumn{2}{c}{ Measure of Prevalence } & \multicolumn{2}{c}{ Measures of Importance } \\
\cline { 2 - 5 } & $\begin{array}{c}\text { Number of } \\
\text { Constructs }\end{array}$ & $\begin{array}{c}\text { Percent Number } \\
\text { of Constructs }\end{array}$ & $\begin{array}{c}\text { Average Percent } \\
\text { Similarity Score }\end{array}$ & $\begin{array}{c}\text { Percent of Scores with } \\
\text { "High" H-I-L Values }\end{array}$ \\
\hline Innovation/industry leadership & 27 & $10.2 \%$ & $48.1 \%$ & $33.3 \%$ \\
Marketing and Sales & 27 & $10.2 \%$ & $44.1 \%$ & $33.3 \%$ \\
Differentiation/competitive advantage & 25 & $9.4 \%$ & $46.2 \%$ & $36.0 \%$ \\
Management/Decision making issues & 25 & $9.4 \%$ & $37.0 \%$ & $36.0 \%$ \\
Customer engagement & 24 & $9.1 \%$ & $39.4 \%$ & $33.3 \%$ \\
Legitimacy/authenticity/integrity & 24 & $9.1 \%$ & $49.8 \%$ & $41.7 \%$ \\
Communication/Education & 22 & $8.3 \%$ & $38.6 \%$ & $31.8 \%$ \\
Control (internal/external) & 20 & $7.5 \%$ & $31.3 \%$ & $20.0 \%$ \\
Identity and image & 19 & $7.2 \%$ & $42.9 \%$ & $42.1 \%$ \\
Product quality/energy efficiency & 17 & $6.4 \%$ & $41.5 \%$ & $35.3 \%$ \\
Environmental impact & 10 & $3.8 \%$ & $39.0 \%$ & $50.0 \%$ \\
Profit (cost/revenue drivers) & 10 & $3.8 \%$ & $42.5 \%$ & $40.0 \%$ \\
Time horizon (short vs. long) & 8 & $3.0 \%$ & $47.5 \%$ & $25.0 \%$ \\
Company View & 6 & $2.3 \%$ & $37.5 \%$ & $16.7 \%$ \\
Miscellaneous & 1 & $0.4 \%$ & $75.0 \%$ & $100.0 \%$ \\
Total & $\mathbf{2 6 5}$ & $\mathbf{1 0 0 . 0 \%}$ & $\mathbf{4 2 . 3 \%}$ & $\mathbf{3 4 . 7 \%}$ \\
\hline
\end{tabular}


The two most common or prevalent themes were Innovation/industry leadership and Marketing and Sales. In other words, home builders' most widely held view of the construal of the drivers/pressures to which they are exposed in making the decision to participate in a voluntary environmental program relate to viewing the decision as a function of seeing themselves as being a leader or innovator in the industry combined with the idea of using the program as a marketing and sales tool. Other themes that were shared by many decision makers related to Differentiation/competitive advantage, Management/ Decision making issues, Customer engagement, and Legitimacy/authenticity/integrity. In other words, the view that the program could help set the firm apart, provide tools for running the company, help focus attention on customers, and ensuring the firm was doing the right thing were also prevalent.

In addition to the frequency or prevalence of constructs, it is also useful to determine how important those constructs are for the interviewees. The importance of constructs can be measured using percent similarly (percent matching) scores and with H-I-L values as previously described. In terms of importance, the category with the highest average percent similarity score was Legitimacy/authenticity/integrity while the Environmental impact theme scored the highest percentage of high H-I-L values. This highlights that the view of the decision to join the program as part of 'building it right' as well as 'doing the right thing for the environment' were most important.

The themes of Environmental impact, Profit (cost/revenue drivers), Time horizon (short vs. long), and Company View were less prevalent or not as widely shared. Themes that were less important in terms of viewing the program were Time horizon (short vs. long) and Company View.

\section{Discussion of the Construct Themes}

In identifying these themes and discussing them in light of the current literature, it should be noted that this study's approach of examining the sensemaking (Weick, 1995) of home builders who made the decision to participate in a voluntary environmental program using Kelly's PCT theory (Kelly, 1955 and 1963) is a relatively novel approach to studying this issue. The predominant themes in the current literature are to study the notion of going green from a competitiveness aspect or to study the motivations behind going green. As this study is looking at the construal of the drivers/pressures to go green, comparisons to the extant literature for the categorization of the elicited constructs are not quite a direct comparison, but rather inferences will be drawn to show areas of alignment and disagreement. The subsequent element analysis of the decision to participate is more in line with previous studies and allows for more direct comparisons between studies.

The following is a discussion of the themes categorized from the construal of the decision to participate.

\section{Innovation/Industry Leadership}

The idea of being a proactive, innovative, and leading firm in the industry was the most widely shared theme in the interviews. High percent similarity scores and a large number of high scores for the H-I-L values also reinforce that this theme was an important way of construing the decision to participate. The theme of innovation/industry leadership mirrors findings by Sharma and Vredenburg (1998) who identified first mover status and innovation as an organizational capability tied to proactive firms. The construal of the decision to participate as being viewed as innovative or leading the industry, also aligns with Chen's (2008) findings on 'green product innovation' and 'green process innovation' that had links to a firm's 'green core competences'. There is also a link to Hart's (1995) natural resource based view of the firm in that being proactive and innovative provides the firm with the opportunity to build invisible assets through greater learning and more time/practice to improve processes. In addition, this finding aligns with Porter's and van der Linde's (1995) perspective that firms actively seek opportunities for environmental innovation. Finally, this finding contrasts with the criticism that Palmer et al (1995) makes of Porter and van der Linde's work with respect to their belief that firms are not vigilantly looking at environmental quality-improving innovations. The results of this study show innovation is top of mind for decision makers. 


\section{Marketing and Sales}

The marketing and sales theme was also tied for the most number of constructs and it scored above the overall average on its percent similarity score (indicating prevalence and importance). With decision makers viewing the program as a sales and marketing tool in terms of driving customer demand and convincing customers, there is an alignment with the current field of green or environmental marketing as described by such authors as Kotler (2011) and Vazifehdust et al (2011). Vazifehdust et al's (2011) description of green marketing activities, such as green positioning, green promotion, and green selling, fit with constructs identified in the marketing and sales theme. These findings also corroborate Chen's (2010) brand equity research into the environmental context, that the green brand image is a driver of green brand equity. In this sense, the decision to participate in a voluntary environmental program is being viewed in light of its potential to increase sales as a way of convincing the customer that the firm and its homes are green.

\section{Differentiation/Competitive Advantage}

The idea of improving the firm's competitive advantage by setting the firm apart from their rivals in the customer's eyes was also a prominent and important way of construing the decision to participate in the program. In the elicitation of constructs, interviewees provided, in their own words, terms like "differentiation", "niche" and "competitive advantage" when describing their decision to participate. This idea of using program participation as a basis for differentiation/competitive advantage aligns with Porter's (1980) work on competitive advantage and the use of focus and differentiation strategies in the marketplace. In this sense, the idea of using the program as a way of setting the company apart in the marketplace was a key way of construing the decision to participate.

\section{Management/Decision Making Issues}

As previously described, constructs provided in the management/decision making issues theme were focused on construing the program as a management or decision making tool. This finding parallels HowardGrenville et al's (2008) finding that there is interplay between internal, managerial factors and corporate environmental practices. This finding is also supportive of Darnall et al's (2000) assertion that firms are adopting environmental programs to help them more effectively and efficiently manage their environmental impact through better integration of environmental concerns throughout their operations. In other words, interviewees were seeing the decision to join the program as a way to help them run their business.

Although viewing the program as an internal management or decision making tool was fairly common, it was relatively unimportant suggesting that it is just one factor taken into account when business decisions in general are made by home builders.

\section{Customer Engagement}

Although the idea of viewing Built Green Canada as a way to engage customers could be tied into marketing and sales elements, there was a common thread that this was really about what was best for the customer or caring for the customer. Although this theme (suggesting that participation in the program is construed as a way of maintaining a focus on the customer) was common, it was relatively less important.

This idea of customer focus aligns with prior empirical studies that looked at the customer as a source of stakeholder pressure (Annandale et al, 2004; Arora and Cason, 1996; Darnall et al, 2000; Henriques and Sadorsky, 1996). In addition, Henriques' and Sadorsky's (2008) review article of the main motivators to participate in a voluntary environmental program identified stakeholder relations as an important driver for firm participation. However, there have been other empirical studies that have found contradictory findings to the importance of customers. The results of this study would refute these findings that customer or consumer pressure was not a factor or reason for participating, for example, Khanna et al (2007) and Wu and Wirkkala (2009) found that consumers were not a source of significant pressure. Both of these studies analyzed data from broad industrial sectors in Oregon which may suggest that the difference in their findings (to this study of home builders in Canada) may be due in part to geographic location and the fact that the home building process is more customer focused than the broader industrial categories used in those studies (e.g. manufacturing and transportation sectors). 


\section{Legitimacy/Authenticity/Integrity}

The legitimacy/authenticity/integrity theme was seen as important as it was the highest scoring theme in terms of average percent similarity score. It also scored above average in terms of the number of high H-I-L values. This theme was also widely held. Constructs related to a belief in values, doing the right thing, being true to one's word, and verifying product environmental performance that were part of this theme are reflective of prior studies that identified trust or ethical considerations as part of the decision to join (Chen, 2010; González-Benito and González-Benito, 2004; Paulraj, 2009). The legitimacy/authenticity/integrity view also aligns with Henriques' and Sadorsky's (2008: 147) work where they state that participation in a voluntary environmental program is, “...particularly useful to firms in establishing intangible values like goodwill, legitimacy, reputation, and trust, which enable an organization to differentiate itself from its competitors and build competitive advantage." A few of the interviewees described their construct with a popular culture reference by mentioning the 'do it right' work of Canadian television personality Mike Holmes who is well known for repairing poorly constructed homes or renovation projects.

\section{Communication/Education}

The idea of informing, explaining, and two-way flows of information was at the midway point in terms of prevalence, and it was generally viewed as less important in terms of its average percent similarity score and average number of high H-I-L values. There is very little in the literature that considers the construal of the decision to join a voluntary environmental program as a communication/education issue explicitly. While there is some reference to using a voluntary environmental program as a stakeholder engagement tool (Henriques and Sadorsky, 2008), the concept of stakeholder engagement in the literature is better aligned with the previously mentioned customer engagement theme. In addition, the constructs provided by the interviewees were more in line with using the program as a tool to facilitate the sharing of information with many parties (both internal and external) as opposed to a singular focus on external engagement.

\section{Control (Internal/External)}

While prior studies on voluntary environmental programs do not focus specifically on issues of control, all of the studies indirectly address it by either examining forces within the company (e.g. González-Benito and González-Benito, 2004; Sharma and Sharma, 2011), external to the company (e.g. Mikler, 2007; Henriques and Sadorsky, 1996), or a combination of both (e.g. Bansal and Roth, 2000; Wu and Wirkkala, 2009). In terms of viewing the decision to participate as a control issue, this theme had the lowest average percent similarity score and second lowest number of high H-I-L values indicating it was relatively unimportant. It was also below the midpoint in terms of prevalence. This theme likely emerged as a result of the interviewees' interpretations of the internal and external nature of the supplied elements used to elicit the constructs.

\section{Identity and Image}

While linkages could be drawn to marketing and sales elements, this theme more precisely related to construing the decision to participate as tied to corporate image and being viewed as a professional builder. Although not as prevalent as other themes, it was seen as important. Chen (2008) reported that firms exhibiting green core competencies witnessed positive effects on their image of being a green company. This finding supports the idea that decision makers view the decision to join a voluntary environmental program as in part to do with their identity and image as a professional or green builder. In addition, while other studies do not specifically name 'identity and image' as part of the construal of the decision to participate, many studies include ideas of identity and image in their discussion of competitiveness (Henriques and Sadorsky, 1996; González-Benito and GonzálezBenito, 2004).

\section{Product Quality/Energy Efficiency}

Intuitively one might expect that part of the construal of the decision to participate in a green building program is to build more energy efficient homes. This study confirms that view with the product quality/energy 
efficiency theme constructs that were shared by about half of the interviewees. It was also relatively important. This supports the notion that builders view the decision to participate in the program as a way to improve product quality/energy efficiency. This underscores Chen's (2006) findings that the more firms invest in green core competences, the better their green product performance.

\section{Environmental Impact}

Also one might expect intuitively the decision to participate in an environmental program to be environmentally motivated. This theme, however, was not widely shared with only 10 constructs being elicited related to 'doing the right thing for the environment'. Although not widely shared, this theme was very important for those interviewees who identified this construct with the highest percent of scores with a high H-I-L value. In other words, for the minority of builders that construed the decision to participate in Built Green Canada as a real environmental focus as opposed to other reasons, it was an important consideration. The idea of joining a voluntary environmental program for truly environmental reasons corresponds to the ecological responsibility element of Bansal's and Roth's (2000) Model of Corporate Ecological Responsiveness. So while this model is very relevant to a few firms' motivations, it does not relate strongly to the motivations of most builders as they themselves construe what affects them.

\section{Profit (Cost/Revenue Drivers)}

The idea of viewing the program in terms of cost and efficiencies as opposed to revenue or cost-recovery was not widely shared nor was it seen as particularly important. While there was a general recognition that environmental actions (e.g. reducing inputs and waste) during the construction process could save the firm money, it was generally reported that the current state of the technology in the industry meant that including additional environmental or energy efficient features added to the costs of the firm. In other words, while the concept of Porter and van der Linde's (1995) innovation offsets were seen as possible in the future, the market was still seen by interviewees as being in the early stages of its life-cycle with costs exceeding benefits. The Government of Canada's national housing agency noted this cost and life cycle issue with their Equilibrium sustainable housing demonstration initiative (Canada Mortgage and Housing Corporation, 2012). They found that environmentally friendly homes had higher upfront costs to build then conventional housing, but they were forecasting as more of these homes are built, experience and demand are expected to increase, driving down the cost of construction over time (Canada Mortgage and Housing Corporation, 2012).

\section{Time Horizon (Short vs. Long)}

The idea of construing the decision to join a voluntary environmental program from a temporal aspect was not widely shared nor was it seen as particularly important. This mirrors the relative scarcity of this topic in the literature. From the interviews, there was not a clear consensus in the constructs of what constituted short versus long term in this theme. Short term horizon descriptions ranged from immediate day-to-day issues to outwards of up to two years. Long term horizon descriptions ranged from as little as two years out to as far out as 'future generations'.

\section{Company View}

This theme of company view had the lowest number of categorized constructs (not widely shared), and it scored below the overall averages for both its percent similarity score and had the lowest score for its average number of high H-I-L values (less important). The low prevalence and importance of this theme is also reflected by its relative absence in the literature. While some studies (e.g. Annandale et al, 2004; Darnall et al, 2010b; Morgenstern and William, 2007) make reference to the sponsorship of a program (public/government voluntary programs, negotiated agreements between business and government, or unilateral agreement by industry firms), the focus of these studies is not related to the construal of the decision to participate. For example, Darnall et al (2010b) looked at the issue of voluntary environmental program sponsorship (government versus industry), that study focused more on the varying level of stakeholder influence as opposed to member views. As the Built Green Canada 
program was created by home builders, this finding would support the notion that joining the program is viewed by some participants as a way to serve for the overall betterment of the industry as opposed to just company gain.

In summary, these findings cast a particular light on what has been known in the literature. Of the factors mentioned by other studies, differentiating the firm through environmental leadership and innovation appear to be particularly important while using environmentally friendly techniques to gain cost efficiencies during construction are less important as construed by the participants in the program.

\section{Elements}

During the RGT interview, all interviewees were presented with an overall supplied construct (Overall, important to my decision to participate - Overall, less important to my decision to participate) - firstly in order to assess the personal importance of the constructs by means of Honey's (1979) technique, (results presented above); and secondly, in order to assess the overall importance of the drivers/pressures.

The interviewees had rated each of the 10 supplied elements on this overall supplied construct using a 5 point scale with a score of 1 representing the 'important to my decision to participate' end of the spectrum and a score of 5 being the 'less important to my decision to participate' end of the spectrum, giving the results as follows.

As this data is ordinal in nature, the most appropriate measure of central tendency and variance are median and percentiles (Stevens, 1946). Table 3 below highlights the results.

Table 3. Summary of Ratings on the Overall Supplied Construct (Importance to Decision to Participate)

\begin{tabular}{|c|c|c|c|c|c|c|c|c|c|c|c|}
\hline & \multicolumn{11}{|c|}{ Element } \\
\hline & Rating & E1 & E2 & E3 & E4 & E5 & E6 & E7 & E8 & E9 & E10 \\
\hline \multirow{5}{*}{ Rating (frequency count) } & 1 & 7 & 2 & 9 & 13 & 0 & 14 & 0 & 9 & 12 & 12 \\
\hline & 2 & 6 & 1 & 11 & 13 & 1 & 9 & 5 & 13 & 10 & 10 \\
\hline & 3 & 5 & 3 & 5 & 4 & 5 & 7 & 5 & 7 & 6 & 7 \\
\hline & 4 & 5 & 11 & 3 & 1 & 8 & 1 & 6 & 2 & 2 & 2 \\
\hline & 5 & 9 & 15 & 4 & 1 & 18 & 1 & 16 & 1 & 2 & 1 \\
\hline Median & & 3 & 4 & 2 & 2 & 5 & 2 & 4.5 & 2 & 2 & 2 \\
\hline $25^{\text {th }}$ Percentile & & 2 & 4 & 1 & 1 & 4 & 1 & 3 & 1 & 1 & 1 \\
\hline $75^{\text {th }}$ Percentile & & 5 & 5 & 3 & 2 & 5 & 3 & 5 & 3 & 3 & 3 \\
\hline
\end{tabular}

Elements that scored relatively high in importance (1 and 2 ratings) were E3 - Handling competition, E4 Appealing to customers, E6 - Acquiring technical knowledge, E8 - Obtaining publicity, E9 - Building corporate culture/identity, and E10 - Obtaining third party certification. These elements had median scores of 2 with $75^{\text {th }}$ percentile scores of 3 or lower (in other words, very few less important ratings).

Elements that scored relatively low in importance (4 and 5 ratings) were E2 - Creating cost efficiencies for your organization, E5 - Responding to suppliers/trades, and E7 - Accessing Government/CMHC Incentives. These elements had median scores of 4 or higher with $25^{\text {th }}$ percentile scores of 3 or higher (in other words, very few more important ratings).

Element E1 - Pre-empting/influencing government legislation (e.g. building code changes) was the only element to score a fairly equal distribution of rating scores.

Overall then, handling competition, appealing to customers, acquiring technical knowledge, obtaining publicity, building corporate culture/identity, and obtaining third party certifications were important drivers/pressures to home builders to participate in the Built Green Canada program. In contrast, creating cost efficiencies, accessing government incentives and responding to trades/suppliers were of low importance.

As table 4 below highlights, the findings of important drivers/pressures are generally in alignment with previous research that identified competitive pressures, culture and identity, information/knowledge gain, publicity and government. Previous studies reported varying results for consumer pressure, but the findings found that appeal 
to customers was of importance. The results did not support the findings of other studies that indicated supplier pressure, cost savings/efficiencies, or incentive mechanisms were important factors in a firm's decision to join a voluntary environmental program.

Table 4. Driver/Pressure Alignment with Other Studies

\begin{tabular}{lcl}
\hline \multicolumn{1}{c}{ Study } & Alignment & \multicolumn{1}{c}{ Areas of Alignment } \\
\hline Arora and Cason (1996) & Agrees & Agrees: consumer contact and public recognition \\
Lyon and Maxwell (1999) & Agrees & Agrees: shape government regulations \\
Videras and Alberini (2000) & Agrees & Agrees: publicity and information/technology transfer \\
Howard-Grenville et al (2008) & Agrees \\
Darnall et al (2000) & Mixed & $\begin{array}{l}\text { Agrees: organizational culture and organizational identity } \\
\text { Agrees: public relations and customer demands }\end{array}$ \\
Annandale et al (2004) & Mixed & $\begin{array}{l}\text { Agrees: customer pressure and corporate culture } \\
\text { Disagrees: cost savings }\end{array}$ \\
González-Benito and González-Benito (2005) & Mixed & $\begin{array}{l}\text { Agrees: competitive motivations } \\
\text { Mixed: stakeholder motivations }\end{array}$ \\
Khanna et al (2007) & Mixed & $\begin{array}{l}\text { Agrees: competitive pressures } \\
\text { Disagrees: consumers pressure } \\
\text { Agrees: knowledge gain and government regulation }\end{array}$ \\
Henriques and Sadorsky (2008) & Mixed & $\begin{array}{l}\text { Disagrees: cost efficiency and incentives } \\
\text { Mixed: stakeholder relations } \\
\text { Agrees: competitive pressures, high costs deter }\end{array}$ \\
Du and Wirkkala (2009) & Mixed & Mixed: stakeholder relations \\
\hline
\end{tabular}

\section{CONCLUSION}

The results provided for the identification of the main ways or themes that decision makers use to construe or view the decision to participate in a voluntary environmental program. It was determined the most widely held construal of the drivers/pressures on the decision to participate were a function of seeing their firm as a leader or innovator in the industry combined with the idea of using the program as a marketing and sales tool. Other views that were identified included the idea that the program could help set the firm apart from its competition, provide tools for running the company, and help focus attention on customers. It was also found that home builder views of 'building it right' as well as 'doing the right thing for the environment' were important in the way they construed the decision to join the program.

An assessment of the importance of the drivers/pressures that influence the decision was also produced. In making a contribution to the knowledge base with respect to supporting prior studies on motivators to go green, the element analysis of the supplied construct provided a number of areas of agreement and disagreement with the extant literature. For the residential construction industry, it was found that six specific drivers/pressures were of particular importance including handling competition, appealing to customers, acquiring technical knowledge, obtaining publicity, building corporate culture/identity, and obtaining third party certifications. These findings were generally in alignment with the literature, although there is disagreement on the importance of customers in some previous studies (see table 4 above).

Drivers/pressures of low importance were found to be cost efficiencies, trades/suppliers, and incentives. These findings, specific to the housing industry, disagreed with prior research that found cost efficiencies (Porter and van der Linde, 1995; Annandale et al, 2004; Henriques and Sadorsky, 2008), stakeholder relations with suppliers (Darnall et al, 2000; Henriques and Sadorsky, 2008), and incentive mechanisms (Henriques and Sadorsky, 2008) as important motivators for firms to go green. The use of incentive-based regulation is supported in the literature (Porter and van der Linde, 1995; Palmer et al, 1995); however, it was found that accessing government incentives was not an important driver/pressure as many interviewees commented that the current value of incentive programs in Canada was not adequate and that firm resources required to administer the incentive programs were not worth the effort. 
In addition to the aforementioned academic contributions, an understanding of the decision to participate in a voluntary environmental program is useful for industry, voluntary environmental program organizations, and government. The results are useful for these groups and government policy makers to provide them with a better understanding of participant motivations leading to program improvements and better marketing of these programs.

\section{Research Limitations}

There are limitations to the generalizeability of the findings based on the chosen research methods and design. As the use of RGT interviews was the research design and primary data collection technique, a discussion of validity and reliability are in order.

Using interviews to collect data is not without limitations. Interview data limitations can include personal bias and lack of awareness by interviewees (Patton, 2002). The use of the RGT was designed to overcome some of these limitations. The RGT is noted for helping remove the influence of the researcher's frame of reference (Diaz de Leon and Guild, 2003), assisting in capturing interviewees' perception of nebulous concepts (Rogers and Ryals, 2007), and minimizing researcher bias (Fassin et al, 2011). In addition, interviews on sensitive topics can lead to social desirability bias as there is a tendency by research participants to describe themselves in favorable terms (Mick, 1996; De Jong et al, 2010). The RGT is useful for addressing social desirability bias with interviewees as the technique allows the researcher to get beneath what an interviewee might view as the right answer (Jankowicz, 2004; Rogers and Ryals, 2007).

In addition, the findings presented are more generalizeable to industries with similar characteristics to home building (e.g. fragmented) and located in regions with business cultures similar to Canada.

\section{Further research}

As mentioned in the previous section on limitations, the generalizeability could be further enhanced with additional studies in other regions and with other voluntary environmental programs. In this sense, a larger study involving home builders across Canada or in other nations would provide a richer picture of the construal of the drivers/pressures to participate. Looking at other voluntary environmental programs beyond Built Green Canada would also have a similar impact.

Further investigation of the Environmental impact theme identified would also be of interest. As previously described, this theme was not overly common in terms of the frequency of its constructs, but it had the highest percent of high H-I-L scores indicating it was important. Further study of this very important but not common theme with more in-depth research of decision maker construal of the environmental aspects/impacts of a voluntary environmental program would be illuminating.

\section{AUTHOR INFORMATION}

Dr. Dustin Quirk is a Business Instructor at Red Deer College where he teaches courses on strategic management and corporate social responsibility. Prior to joining Red Deer College, Dr. Quirk worked for over 5 years in various government policy and economic roles related to housing market analysis and industry liaison. His research interests include residential construction (housing), business sustainability, and business education. He has a Doctor of Business Administration and a Master of Science in Strategic Planning from the Edinburgh Business School at Heriot-Watt University, a Master of Public Administration from Dalhousie University, and a Bachelor of Education from the University of Alberta. E-mail: dustin.quirk@rdc.ab.ca

Professor Jankowicz holds the Chair of Constructivist Managerial Psychology at Edinburgh Business School, Heriot Watt University, where he teaches Research Methods on the MSc and DBA programmes, and supervises doctoral candidates. He is also a member of the DBA Research Committee. Prior to this time, he held a chair at the University of Bedfordshire, permanent Readership and Lecturer positions at universities in the UK and Ireland, and visiting posts at New Mexico State University, USA, and the Academy of Economics in Krakow, Poland. His teaching and research focuses on research methods in business and management (especially those reflecting a 
constructivist epistemology); personal construct psychology and the transfer of knowledge across cultural boundaries, with particular reference to the post-command economies of central Europe; and distance learning techniques. Among his consultancy clients are NASA (JPL Pasadena), Unilever, Davis Venture Capital, and Rolls Royce (Bristol).

\section{REFERENCES}

Alberta. Ministry of Municipal Affairs. (2011) Building. Retrieved from: http://www.municipalaffairs.alberta.ca/cp_building.cfm

Alberta. Ministry of Municipal Affairs. (2012) Energy Efficiency and the Alberta Building Code. Retrieved from: $\mathrm{http} / / /$ www.municipalaffairs.alberta.ca/CP_EnergyCodes.cfm

Anseel, F., Lievens, F., Schollaert, E., and Choragwicka, B. (2010) Response Rates in Organizational Science, 1995-2008: A Meta-analytic Review and Guidelines for Survey Researchers, Journal of Business \& Psychology, 25(3), 335-349.

Annandale, D., Morrison-Saunders, A. and Bouma, G. (2004) The impact of voluntary environmental protection instruments on company environmental performance, Business Strategy and the Environment, 13(1), 1-12.

Arora, S. and Cason, T.N. (1996) Why do firms volunteer to exceed environmental regulations? Understanding participation in EPAs 33/50 program, Land Economics, 72(4), 413-433.

Bansal, P. and Roth, K. (2000) Why Companies Go Green: a Model of Ecological Responsiveness, Academy of Management Journal, 43(4), 717-736.

Benjafield, J.G. (2008) George Kelly: Cognitive Psychologist, Humanistic Psychologist, or Something Else Entirely?, History of Psychology, 11(4), 239-262.

Blackman, A., Darley, S., Lyon, T.P. and Wernstedt, K. (2010) What Drives Participation in State Voluntary Cleanup Programs? Evidence from Oregon, Land Economics, 86(4), 785-799.

Branco, M. and Rodrigues, L. (2006) Corporate Social Responsibility and Resource-Based Perspectives, Journal of Business Ethics, 69(2), 111-132.

Built Green Canada. (2011a) About Built Green. Retrieved from: http://www.builtgreencanada.ca/about-builtgreen

Built Green Canada. (2011b) Our Purpose. Retrieved from: http://www.builtgreencanada.ca/our-purpose

Butt, T. and Burr, V. (2004) Invitation to Personal Construct Psychology. London, Whurr Publishers.

Canada. Canada Mortgage and Housing Corporation. (2010) Canadian Housing Observer. Ottawa, ON, Canada Mortgage and Housing Corporation.

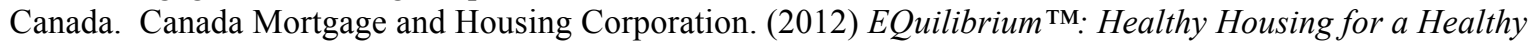
Environment. Retrieved from: http://www.cmhc-schl.gc.ca/en/co/maho/yohoyohe/yohoyohe_001.cfm

Chen, Y. (2008) The Driver of Green Innovation and Green Image - Green Core Competence, Journal of Business Ethics, 81(3), 531-543.

Clarkson, P.M., Li, Y., Richardson, G.D. and Vasvari, F.P. (2011) Does it really pay to be green? Determinants and consequences of proactive environmental strategies, Journal of Accounting and Public Policy, 30(2), 122-144.

Creswell, J.W. (2003) Research Design: Qualitative, Quantitative, and Mixed Method Approaches. Thousand Oaks, California, Sage Publications.

Crotty, M. (1998) The Foundations of Social Research: Meaning and Perspective in the Research Process. Thousand Oaks, California, Sage Publications.

Darnall, N., Gallagher, D.R., Andrews, R. and Amaral, D. (2000) Environmental Management Systems: Opportunities for Improved Environmental and Business Strategy?, Environmental Quality Management, 9(3), $1-9$.

Darnall, N., Henriques, I. and Sadorsky, P. (2010a) Adopting Proactive Environmental Strategy: The Influence of Stakeholders and Firm Size, Journal of Management Studies, vol. 47, no. 6, pp. 1072-1094.

Darnall, N., Potoski, M. and Prakash, A. (2010b) Sponsorship Matters: Assessing Business Participation in Government- and Industry-Sponsored Voluntary Environmental Programs, Journal of Public Administration Research and Theory, 20(2), 283-307.

De Jong, M., Pieters, R., and Fox, J. (2010) Reducing Social Desirability Bias Through Item Randomized Response: An Application to Measure Underreported Desires, Journal of Marketing Research, 47(1), 14-27.

Diaz de Leon, E. and Guild, P. (2003) Using repertory grid to identify intangibles in business plans, Venture Capital, 5(2), 135-160.

Eisenhardt, K. (1989) Building Theories from Case Study Research, Academy of Management Review, 14(4), 532- 
550.

Fassin, Y. and Van Rossem, A. (2009) Corporate Governance in the Debate on CSR and Ethics: Sensemaking of Social Issues in Management by Authorities and CEOs, Corporate Governance: An International Review, 17(5), 573-593.

Fassin, Y., Van Rossem, A. and Buelens, M. (2011) Small-Business Owner-Managers' Perceptions of Business Ethics and CSR-Related Concepts, Journal of Business Ethics, 98(3), 425-453.

Fransella, F., Bell, R., and Bannister, D. (2004) A Manual for Repertory Grid Technique. Second Edition. England: John Wiley and Sons, Ltd.

Georg, S. and Füssel, L. (2000) Making Sense of Greening and Organizational Change, Business Strategy \& the Environment, 9(3), 175-185.

González-Benito, J. and González-Benito, Ó. (2004) A Study of the Motivations for the Environmental Transformation of Companies, Industrial Marketing Management, 34(5), 462-475.

González-Benito, J. and González-Benito, Ó. (2005) An Analysis of the Relationship Between Environmental Motivations and ISO14001 Certification, British Journal of Management, 16(2), 133-148.

Hart, S.L. (1995) A Natural-Resource-Based View of the Firm, Academy of Management Review, 20(4), 986-1014.

Hart, S.L. (1997) Beyond Greening: Strategies for a Sustainable World, Harvard Business Review, 75(1), 66-76.

Henriques, I. and Sadorsky, P. (1996) The Determinants of An Environmentally Responsive Firm: An Empirical Approach, Journal of Environmental Economics and Management, 30(3), 381-396.

Henriques, I. and Sadorsky, P. (2008) Voluntary Environmental Programs: A Canadian Perspective, Policy Studies Journal, 36(1), 143-166.

Honey, P. (1979) The Repertory Grid in Action: How to Use It to Conduct an Attitude Survey, Industrial and Commercial Training, 11(11), 452-459.

Howard-Grenville, J., Nash, J. and Coglianese, C. (2008) Constructing the License to Operate: Internal Factors and Their Influence on Corporate Environmental Decisions, Law and Policy, 30(1), 73-107.

Jankowicz, A. D. (1987) Whatever Became of George Kelly? Applications and Implications, American Psychologist, 42(5), 481-487.

Jankowicz A. D. (2004) The Easy Guide to Repertory Grids. England, John Wiley and Sons Ltd.

Kansal, R. and Kadambari, G. (2010) Green Buildings: An Assessment of Life Cycle Cost, IUP Journal of Infrastructure, 8(4), 50-57.

Kelly, G. A. (1955) The Psychology of Personal Constructs. New York, Norton.

Kelly, G. A. (1963) A Theory of Personality. New York, Norton.

Khanna, M. and Anton, W. (2002) Corporate Environmental Management: Regulatory and Market-Based Incentives, Land Economics, 78(4), 539-558.

Khanna, M., Koss, P., Jones, C. and Ervin, D. (2007) Motivations for Voluntary Environmental Management, Policy Studies Journal, 35(4), 751-772.

Kotler, P. (2011) Reinventing Marketing to Manage the Environmental Imperative, Journal of Marketing, 75(4), 132-135.

Lindebaum, D. and Cassell, C. (2012) A Contradiction in Terms? Making Sense of Emotional Intelligence in a Construction Management Environment, British Journal of Management, 23(1), 65-79.

Lynes, J.K. and Dredge, D. (2006) Going Green: Motivations for Environmental Commitment in the Airline Industry. A Case Study of Scandinavian Airlines, Journal of Sustainable Tourism, 14(2), 116-138.

Lyon, T.P. and Maxwell, J.W. (1999) Corporate Environmental Strategies as Tools to Influence Regulation, Business Strategy and the Environment, 8(3), 189-196.

Menguc, B. and Ozanne, L.K. (2005) Challenges of the Green Imperative: A Natural Resource-Based Approach to the Environmental Orientation-Business Performance Relationship, Journal of Business Research, 58(4), 430438.

Mick, D. (1996) Are Studies of Dark Side Variables Confounded by Socially Desirable Responding? The Case of Materialism, Journal of Consumer Research, 23(2), 106-119.

Mikler, J. (2007) Varieties of Capitalism and the Auto Industry's Environmental Initiatives: National Institutional Explanations for Firms Motivations, Business \& Politics, 9(1), 1-38.

Miles, M. and Huberman, A. (1994). Qualitative Data Analysis (2nd Edition). Thousand Oaks, California, Sage Publications.

Molina-Azorín, J., Claver-Cortés, E., López-Gamero, M., and Tan, J. (2009) Green Management and Financial Performance: A Literature Review, Management Decision, 47(7), 1080-1100. 
Palmer, K., Oates, W., and Portney, P. (1995) Tightening Environmental Standards: The Benefit-Cost or the NoCost Paradigm?, Journal Of Economic Perspectives, 9(4), 119-132.

Paulraj, A. (2009) Environmental Motivations: A Classification Scheme and its Impact on Environmental Strategies and Practices, Business Strategy and the Environment, 18(7), 453-468.

Patton, M. (2002) Qualitative research and evaluation methods. Thousand Oaks, California, Sage Publications.

Perreault Jr., W. and Leigh, L. (1989) Reliability of Nominal Data Based on Qualitative Judgments, Journal of Marketing Research, 26(2), 135-148.

Porter, M.E. (1980) Competitive Strategy: Techniques for Analyzing Industries and Competitors. New York, Free Press.

Porter, M.E. and van der Linde, C. (1995) Toward a New Conception of the Environment-Competitiveness Relationship, Journal of Economic Perspectives, 9(4), 97-118.

Prakash, A. (2001) Why Do Firms Adopt 'Beyond-Compliance' Environmental Policies?, Business Strategy and the Environment, 10(5), 286-299.

Raskin, J. (2011) On Essences in Constructivist Psychology, Journal of Theoretical and Philosophical Psychology, 31(4), 223-239.

Rogers, B. and Ryals, L. (2007) Using the Repertory Grid to Access the Underlying Realities in Key Account Relationships, International Journal of Market Research, 49(5), 595-612.

Sharma, P. and Sharma, S. (2011) Drivers of Proactive Environmental Strategy in Family Firms, Business Ethics Quarterly, 21(2), 309-334.

Sharma, S. and Vredenburg, H. (1998) Proactive Corporate Environmental Strategy and the Development of Competitively Valuable Organizational Capabilities, Strategic Management Journal, 19(8), 729-754.

Siegel, D.S. (2009) Green Management Matters Only If It Yields More Green: An Economic/Strategic Perspective, Academy of Management Perspectives, 23(3), 5-16.

Snape, D. and Spencer, L. The Foundations of Qualitative Research. In: Ritchie, J. and Lewis, J. (2003) Qualitative Research Practice. London, Sage Publications Ltd.

Stanwick, P.A. and Stanwick, S.D. (2001) CEO Compensation: Does it Pay to Be Green?, Business Strategy and the Environment, 10(3), 176-182.

Stevens, S. S. (1946) On the Theory of Scales of Measurement, Science, 103, 677-680.

Tan, F. and Hunter, M. (2002) The Repertory Grid Technique: A Method for the Study of Cognition in Information Systems, MIS Quarterly, 26(1), 39-57.

Tran, B. (2009) Green Management: The Reality of Being Green in Business, Journal of Economics, Finance \& Administrative Science, 14(27), 21-45.

Vazifehdust, H., Taghipourian, M., and Gharib, Z. (2011) Social Marketing, Green Marketing: The Extension of Marketing Concept, European Journal of Economics, Finance \& Administrative Sciences, 41, 20-33.

Videras, J., and Alberini, A. (2000) The Appeal of Voluntary Environmental Programs: Which Firms Participate and Why?, Contemporary Economic Policy, 18(4), 449-461.

Webb, K. (2004) Voluntary Codes: Private Governance, The Public Interest and Innovation. Ottawa, Canada: Carleton Research Unit for Innovation, Science and Environment.

Weick, K. (1995) Sensemaking in Organizations. Thousand Oaks, Sage Publications.

Wu, J. and Wirkkala, T.M. (2009) Firms' Motivations for Environmental Overcompliance, Review of Law and Economics, 5(1), 400-433. 


\section{APPENDIX 1: GLOSSARY OF KEY TERMS}

\begin{tabular}{ll}
\hline Built Green Canada & $\begin{array}{l}\text { A voluntary environmental program that provides third party certification for homes } \\
\text { that are built environmentally friendly in terms of construction practices and ongoing } \\
\text { operations (e.g. energy efficient and indoor air quality) (Built Green Canada, 2011a). }\end{array}$ \\
\hline Constructs & $\begin{array}{l}\text { Constructs can be regarded as an individual set of perspectives people use to } \\
\text { structure, interpret and anticipate events (Tan and Hunter, 2002; Benjafield, 2008). }\end{array}$ \\
\hline Elements & $\begin{array}{l}\text { The basic components of a person's attention when s/he construes an issue; the } \\
\text { constituents being construed (Fransella et al, 2004; Jankowicz, 2004). }\end{array}$ \\
\hline Going Green & $\begin{array}{l}\text { Going Green is adopting a proactive environmental response including such } \\
\text { operational activities as emissions reductions, reduced energy and resource } \\
\text { consumption and reduced waste generation to developing longer lasting, more } \\
\text { efficient, and/or more environmentally responsible products (Henriques and }\end{array}$ \\
& Sadorsky, 1996; Bansal and Roth, 2000; Tran, 2009). \\
\hline Personal Construct & $\begin{array}{l}\text { A constructivist theory of cognition developed by George Kelly in his 1955 } \\
\text { publication The Psychology of Personal Constructs. Kelly's (1955) fundamental } \\
\text { postulate and 11 corollaries provide the basis of Personal Construct Psychology } \\
\text { (PCP) and Personal Construct Theory (PCT). }\end{array}$ \\
\hline Repertory Grid Technique & $\begin{array}{l}\text { The Repertory Grid Technique is an interviewing technique designed as an } \\
\text { instrument for eliciting personal constructs (Kelly, 1955). }\end{array}$ \\
\hline RGT) & $\begin{array}{l}\text { Sensemaking is the making of sense; the mental processes by which we attribute } \\
\text { meaning to our experiences (Weick, 1995). }\end{array}$ \\
\hline Voluntary Environmental & $\begin{array}{l}\text { A Voluntary Environmental Program is a voluntary code for firms with the } \\
\text { following characteristics (Webb, 2004): } \\
\text { Program (VEP) }\end{array}$ \\
$\begin{array}{l}\text { i. commitments are not required by legislation or regulations; } \\
\text { ii. } \quad \text { they are agreed to by one or more individuals or organizations; }\end{array}$ \\
$\begin{array}{l}\text { iii. they are intended to influence or control behaviour; and } \\
\text { iv. they are to be applied in a consistent manner or to reach a consistent outcome. }\end{array}$ \\
\hline
\end{tabular}

